\title{
Analysis of SNP-SNP interactions and bone quantitative ultrasound parameter in early adulthood
}

\author{
María Correa-Rodríguez ${ }^{1 *}$ D , Sebastien Viatte ${ }^{2}$, Jonathan Massey ${ }^{2}$, Jacqueline Schmidt-RioValle ${ }^{1}$, \\ Blanca Rueda-Medina ${ }^{1+}$ and Gisela Orozco ${ }^{2+}$
}

\begin{abstract}
Background: Osteoporosis individual susceptibility is determined by the interaction of multiple genetic variants and environmental factors. The aim of this study was to conduct SNP-SNP interaction analyses in candidate genes influencing heel quantitative ultrasound (QUS) parameter in early adulthood to identify novel insights into the mechanism of disease.

Methods: The study population included 575 healthy subjects (mean age 20.41; SD 2.36). To assess bone mass QUS was performed to determine Broadband ultrasound attenuation (BUA, dB/MHz). A total of 32 SNPs mapping to loci that have been characterized as genetic markers for QUS and/or BMD parameters were selected as genetic markers in this study. The association of all possible SNP pairs with QUS was assessed by linear regression and a SNP-SNP interaction was defined as a significant departure from additive effects.

Results: The pairwise SNP-SNP analysis showed multiple interactions. The interaction comprising SNPs rs9340799 and rs3736228 that map in the ESR1 and LRP5 genes respectively, revealed the lowest $p$ value after adjusting for confounding factors ( $p$-value $=0.001, \beta(95 \% \mathrm{Cl})=14.289(5.548,23.029)$. In addition, our model reported others such as TMEM135-WNT16 $(p=0.007, \beta(95 \% \mathrm{Cl})=9.101(2.498,15.704)$, ESR1-DKK1 $(p=0.012, \beta(95 \% \mathrm{Cl})=13.641(2$. $959,24.322)$ or OPG-LRP5 $(\mathrm{p}=0.012, \beta(95 \% \mathrm{Cl})=8.724(1.936,15.512)$. However, none of the detected interactions remain significant considering the Bonferroni significance threshold for multiple testing $(p<0.0001)$.

Conclusion: Our analysis of SNP-SNP interaction in candidate genes of QUS in Caucasian young adults reveal several interactions, especially between ESR1 and LRP5 genes, that did not reach statistical significance. Although our results do not support a relevant genetic contribution of SNP-SNP epistatic interactions to QUS in young adults, further studies in larger independent populations would be necessary to support these preliminary findings.
\end{abstract}

Keywords: Gene interaction, Quantitative ultrasound, Candidate gene

\section{Background}

Osteoporosis represents an important public health problem worldwide that triggers near 9 million fractures annually [1]. Its prevalence is increasing due to the ageing of the population [2]. Osteoporosis is characterized by a deterioration of bone tissue microarchitecture that leads to low bone mineral density (BMD) and an

\footnotetext{
* Correspondence: macoro@ugr.es

${ }^{\dagger}$ Equal contributors

${ }^{1}$ Faculty of Health Sciences, University of Granada, Av. Ilustración, 60, 18016

Granada, Spain

Full list of author information is available at the end of the article
}

increased risk of bone fragility fractures [3]. As occurs in many complex diseases, it is widely accepted that osteoporosis individual susceptibility is determined by the interaction of multiple genetic variants and environmental factors $[4,5]$.

An important determinant of osteoporosis risk later in life is the peak bone mass (PBM) [6]. Enhancing bone mass accrual to maximize PBM, which is attained by early adulthood, could help in the elderly to reduce the risk of fracture [6]. Current evidence suggests that genetic factors are major contributors to regulation of PBM, accounting for $50 \%$ and $80 \%$ of the variance in 
BMD [7, 8]. Therefore, identifying genetic factors affecting bone mass in early adulthood would be worthwhile.

Recently, it has been demonstrated that QUS predicts fracture independently of BMD $[9,10]$. QUS provides information about bone mass and other quality aspects which may be of relevance in determining fracture risk such as bone microstructure, elasticity or connectivity $[11,12]$. Besides this, previous studies have shown the ability of heel QUS to predict independently fracture risk $[11,13]$. Compared to dual-energy $\mathrm{x}$-ray absorptiometry (DXA), QUS is more easily accessible, low-cost, noninvasive and non-ionizing [14].

To identify the genetic factors underlying osteoporosis susceptibility, extensive genetic studies have been conducted reporting association of several genetic variants with different bone phenotypes [15-18]. However, these explain little of the heritability in complex phenotypes [19]. The missing heritability problem refers to the observation that the number of significant associations discovered does not form a substantial proportion of heritability for most traits. Thus, SNP-SNP interactions could help explain the missing heritability of common complex traits and therefore, their identification is considered of relevance. To date, only a few studies have been performed to identify SNP-SNP interactions influencing osteoporosis-related traits [20-26]. Most of them have investigated BMD determined by DXA, and therefore the possible influence of genetic interactions on QUS parameters is still unknown [25-27].

The independent association between single nucleotide polymorphisms (SNPs) in WNT16 (rs2908007, rs2908004, and rs2707466) [18, 28, 29], RSPO3 (rs774121) [18] and LRP5 (rs3736228) [30] genes and QUS parameters have been well established. In previous replication studies from our group we investigated the implication of 32 genetic markers reported to influence QUS and/or BMD parameters, and confirmed that WTN16, RSPO3 and LRP5 are genetic factors that determine bone mineralization in young adults $[28,30]$.

Taking into consideration all this evidence, and bearing in mind that it is likely that interactions of common variants at different loci are influencing QUS traits, the aim of this study was to identify SNP-SNP interactions between SNPs independently associated with QUS, that could contribute to QUS traits variation in early adulthood.

\section{Methods}

\section{Study subjects}

A total of 575 Caucasian healthy individuals (400 females and 175 males, median age 20,41 $\pm 2,69$ recruited from different centres of Granada (Spain) composed the study population after giving written informed consent. Local ethics committees approved the study that was conducted following the Declaration of Helsinki. Were excluded from the study those individuals who reported therapy with hormonal contraceptives, diseases of metabolic or endocrine systems and history of bone disease.

\section{Covariates}

A body composition analyzer (TANITA BC-418MA) was used to estimate weight, fat mass and lean mass to the nearest $0,11 \mathrm{Kg}$. Height measurement was performed with a Harpenden stadiometer (Holtain $602 \mathrm{VR}^{\circ}$ ) to the nearest $0,1 \mathrm{~cm}$. Body mass index (BMI) was calculated as weight divided by height squared $\left(\mathrm{kg} / \mathrm{m}^{2}\right)$. Physical activity (PA) was quantified using the short form and selfadministered version of the International Physical Activity Questionnaire (IPAQ) [31]. Dietary calcium intake (DCI) was obtained from a $72 \mathrm{~h}$ recall method including intakes on Thursday, Friday, and Saturday. During the interviews and for a better precision of the food records, pictorial food models and standard household measures were used. All the $72 \mathrm{~h}$ recall were computerized with a nutrient analysis program (Nutriber 1.1.5) to convert food records into amounts of nutrients intake.

\section{QUS of the heel}

Ultrasound measurements (BUA, $\mathrm{dB} / \mathrm{MHz}$ ) were performed using the CUBA clinical ultrasound bone densitometer (McCue Ultrasonic Limited, Compton, Winchester, UK) at the right calcaneus to assess bone mass. This localization was selected on the basis of its accessibility and its high content of trabecular bone [32]. To guarantee the long-term stability of the ultrasound bone densitometer, daily calibrations were performed using a with physical phantom.

\section{SNPs selection and genotyping process}

A total of 32 SNPs mapping to loci that have been characterized as genetic markers for QUS and/or BMD parameters were selected.

DNA was extracted from saliva samples collected from all study participants with the 500 Collection Kit (DNA Genotek Inc., Ontario, Canada).

Genotyping was carried out using a custom design TaqMan OpenArray (Life Technologies, Carlsbad, CA, USA). Genotyping plate containing a predesigned TaqMan genotyping assay for every polymorphism was conducted in the Genomic and Genotyping unit of GENYO centre (Pfizer-University of Granada-Junta de Andalucía Centre for Genomics and Oncological Research). The amplification reaction was performed following the conditions recommended by the manufacturer. For detection of the fluorescence and interpretation of the genotyping results 
the QuantStudio 12 K Flex Real-Time PCR System (Applied Biosystems) was used.

All the Taqman assays included in the array showed a genotyping call rate above $95 \%$. The accuracy of the genotyping process was verified including in all plates negative controls and duplicate samples. We observed $100 \%$ reproducibility.

\section{Statistical analysis}

For all analyses the genotype of each SNP was encoded as $0,1,2$, where 0 and 2 denotes homozygotes with major allele and minor allele respectively and 1 codes heterozygotes.

The Pearson's goodness-of-fit $X^{2}$ test was used to assess the Hardy-Weinberg equilibrium (HWE). First, to reduce redundancy between SNPs, only one SNP out of all SNPs in strong pairwise linkage disequilibrium $\left(\mathrm{r}^{2}>0.90\right)$ was kept, leading to the final inclusion of 30 SNPs (rs2707466 and rs7988338 were excluded) (Table 1). All possible pairwise SNP-SNP interactions between the selected 30 SNPs (435 possible interactions) were assessed by bivariate linear regression modelling of QUS measurements. Linear regression analyses were adjusted for the following covariates: sex, age, BMI, physical activity and calcium intake. The interaction between $\mathrm{SNP}_{1}$ and $\mathrm{SNP}_{2}$ was defined as the additional effect of their concomitant carriage on QUS over the addition of their independent effects (departure from additivity): $\beta_{\text {in }}$ teraction $=\beta_{\text {observed }}-\beta_{\text {expected }}$ with $\beta_{\text {expected }}=\beta_{\mathrm{SNP} 1}+\beta_{\mathrm{SNP} 2}$, where $\beta_{\text {observed }}$ is the observed effect of the concomitant carriage of $\mathrm{SNP}_{1}$ and $\mathrm{SNP}_{2}$ (versus no carriage) in a bivariate linear regression, $\beta_{\mathrm{SNP} 1}$ is the effect ( $\beta$ coefficient) of $\mathrm{SNP}_{1}$ in the absence of $\mathrm{SNP}_{2}, \beta_{\mathrm{SNP} 2}$ is the effect of $\mathrm{SNP}_{2}$ in the absence of $\mathrm{SNP}_{1}$ in the same bivariate regression framework (bivariate refers only to the number of genetic markers (SNPs), as non-genetic covariates have systematically been included for all analyses). The results were reported as $\beta_{\text {interaction }}$ (change of the outcome variable QUS with 95\% confidence intervals (CIs). To all associations, the highly conservative Bonferroni correction considering the number of tested SNPs was applied. The cut-off value for significance was set at $\mathrm{p}<0.0001(0.05 / 435)$. The STATA software was used to perform statistical analyses (version 11.0; STATA Corporation, College Station, TX).

\section{Results}

The characteristics of the 575 study subjects have been published previously [28]. Table 1 shows marker information, including rsID and minor allele frequency (MAF) for 32 SNPs genotyped. All the SNPs were in HWE and none failed the frequency $(\mathrm{MAF}<0.01)$ or missingess (genotyping $>0.05$ ) tests.
The pairwise SNP-SNP interactions tested by linear regression showed multiple interactions (Table 2). The interaction comprising SNPs rs9340799 and rs3736228 that map in the ESR1 and LRP5 genes respectively, revealed the lowest $p$ value (0.001) after adjusting for sex, age, BMI, physical activity and calcium intake. This interaction amounted to a $\beta(95 \% \mathrm{CI})=14.289$ (5.548, 23.029). Interestingly, we found several interactions between different polymorphisms in these genes, further supporting the presence of epistasis between these two loci (rs556442 in LRP5 and rs9340799 in ESR1; rs2234693 in ESR1 and rs3736228 in LRP5; rs2306862 in LRP5 and rs9340799 in ESR1; rs556442 in LRP5 and rs2234693 in ESR1). However, none of the pairwise SNP-SNP tests reached the significant cut off $p$ value considering the Bonferroni correction for multiple testing $(p=0.0001)$.

On the other hand, our analyses revealed SNP-SNP interactions within the same genes (rs2908004 and rs3801387 in WNT16; rs3736228 and rs2306862 in LRP5; rs2982552 and rs3020331 in ESR1; rs2982552 and rs9340799 in ESR1).

\section{Discussion}

In this study, we aimed to provide a more comprehensive view of the genetic architecture underlying QUS by analysing two-way interactions between common SNPs in candidate genes. A number of SNPs in candidate genes were analysed considering potentially important covariates for bone mineralization process such as, age, sex, calcium intake, physical activity and BMI.

This study is the first to investigate SNP-SNP interactions with heel QUS trait. Our findings identified several SNP-SNP interactions, highlighting that observed between rs9340799 in ESR1 and rs3736228 in LRP5. However, the results from these analyses should be interpreted with caution since SNP-SNP interactions did not reach the highly conservative Bonferroni significance threshold for multiple testing $(\mathrm{p}<0.0001)$. Even though these data suggest that epistatic SNP-SNP interactions does not influence heel ultrasound measurements in young Caucasian adults, the possibility of a false negative due to a limited statistical power cannot be excluded.

Oestrogen action in bone are mediated mainly through ER $\alpha$ codified by the ESR1 gene, which has been associated with different osteoporosis related traits in previous studies [33]. The positive effects of the oestrogens on the skeleton have been well established; oestrogens play a major role in the aetiology of osteoporosis by the regulation of bone turnover and inhibition of bone loss [34]. These biological effects are mediated by binding and activation of specific oestrogen receptors (ER $\alpha$ and ER $\beta$ ) [35]. The rs9340799 variant is located in the first intron of the ESR1 gene and although this intron may contain 
Table 1 General information for the studied single nucleotide polymorphisms (SNPs)

\begin{tabular}{|c|c|c|c|c|c|}
\hline Chromosome & Gene & SNP & Allele & MAF in this study & HWE (p) \\
\hline 2 & SPTBN1 & rs11898505 & $G>A$ & 0.37 & 0.75 \\
\hline 6 & RSPO3 & rs7741021 & $A>C$ & 0.39 & 0.84 \\
\hline 6 & $C C D C 170$ & rs4869739 & $A>T$ & 0.35 & 0.22 \\
\hline 6 & ESR1 & rs3020331 & $C>T$ & 0.43 & 0.10 \\
\hline 6 & ESR1 & rs2982552 & $C>T$ & 0.49 & 0.19 \\
\hline 6 & ESR1 & rs2234693 & $\mathrm{T}>\mathrm{C}$ & 0.44 & 0.19 \\
\hline 6 & ESR1 & rs9340799 & $A>G$ & 0.34 & 0.75 \\
\hline 7 & WNT16 & rs2908007 & $\mathrm{T}>\mathrm{C}$ & 0.18 & 0.33 \\
\hline 7 & WNT16 & rs2908004 & $T>C$ & 0.22 & 0.25 \\
\hline 7 & WNT16 & rs3801387 & $\mathrm{T}>\mathrm{C}$ & 0.10 & 0.78 \\
\hline 7 & WNT16 & rs3801385 & $A>G$ & 0.09 & 0.33 \\
\hline 7 & WNT16 & rs 2707466 & $G>A$ & 0.22 & 0.39 \\
\hline 7 & WNT16 & rs2536184 & $G>A$ & 0.03 & 0.09 \\
\hline 8 & $O P G$ & rs4355801 & $A>G$ & 0.39 & 0.17 \\
\hline 8 & $O P G$ & rs3102735 & $\mathrm{T}>\mathrm{C}$ & 0.12 & 0.35 \\
\hline 8 & $O P G$ & rs2073618 & $G>C$ & 0.46 & 0.63 \\
\hline 10 & DKK1 & rs7902708 & $G>C$ & 0.11 & 0.77 \\
\hline 11 & TMEM135 & rs597319 & $A>G$ & 0.31 & 0.19 \\
\hline 11 & LRP5 & rs 2306862 & $C>T$ & 0.19 & 0.32 \\
\hline 11 & LRP5 & rs556442 & $A>G$ & 0.42 & 0.88 \\
\hline 11 & LRP5 & rs3736228 & $C>T$ & 0.17 & 0.46 \\
\hline 13 & RANKL & rs9594759 & $T>C$ & 0.48 & 0.40 \\
\hline 13 & RANKL & rs12585014 & $G>A$ & 0.18 & 0.11 \\
\hline 13 & RANKL & rs7988338 & $G>A$ & 0.19 & 0.40 \\
\hline 13 & RANKL & rs2148073 & $C>G$ & 0.18 & 0.60 \\
\hline 17 & SOST & rs4792909 & $G>T$ & 0.42 & 0.31 \\
\hline 17 & SOST & rs851054 & $A>G$ & 0.38 & 0.06 \\
\hline 17 & SOST & rs2023794 & $\mathrm{T}>\mathrm{C}$ & 0.05 & 0.18 \\
\hline 18 & RANK & rs1805034 & $C>T$ & 0.41 & 0.26 \\
\hline 18 & RANK & rs12458117 & $G>A$ & 0.19 & 0.35 \\
\hline 18 & RANK & rs3018362 & $A>G$ & 0.32 & 0.18 \\
\hline 19 & GPATCH1 & rs10416265 & $A>G$ & 0.32 & 0.06 \\
\hline
\end{tabular}

$M A F$ minor allele frequency, $H W D \mathrm{p}$ value for Hardy-Weinberg equilibrium

regulatory elements, the functional implication of this genetic variant remains unknown. In addition, lowdensity lipoprotein receptor-related protein 5 (LRP5) codifies a protein belonging to the Wnt canonical signal, which regulates osteoblast and osteocyte function [36]. Similarly, the functional relevance of the rs3736228 SNP located in LRP5 is still unknown [37,38].

The results of this study could be suggestive of a wellregulated cross-talk between ESR1 and LRP5 genes in bone physiology. Although ESR1 and LRP5 develop different roles in skeletal homeostasis, they could be interacting in bone cell biology through synergistic or antagonistic actions. It could be hypothesised that individuals carrying risk alleles at rs9340799 and rs3736228 SNPs have a lower expression of both ESR1 and LRP5, which could lead to an impaired bone mass. As we have analysed a cohort including only young adults, our findings also may suggest that the interaction between rs9340799 and rs3736228 SNPs might be implicated in bone mass accrual. Although previous studies have reported the individual contribution of these polymorphisms to osteoporosis-related phenotypes in early adulthood [30, 38-41], the molecular mechanisms through which these polymorphisms might interact are still under investigation. Future studies are required to elucidate the molecular mechanisms by this interaction 
Table 2 Gene-gene interaction analysis

\begin{tabular}{|c|c|c|c|c|c|}
\hline SNP1 & Gene 1 & SNP2 & Gene 2 & $\beta(95 \% \mathrm{Cl})$ & $p$-value \\
\hline rs9340799 & ESR1 & rs3736228 & LRP5 & $14.289(5.548,23.029)$ & 0.001 \\
\hline rs2908004 & WNT16 & rs3801387 & WNT16 & $77.350(25.890,128.808)$ & 0.003 \\
\hline rs597319 & TMEM135 & rs2908004 & WNT16 & $9.101(2.498,15.704)$ & 0.007 \\
\hline rs3736228 & LRP5 & rs2306862 & LRP5 & $23.476(5.623,41.327)$ & 0.010 \\
\hline rs9340799 & ESR1 & rs7902708 & DKK1 & $13.641(2.959,24.322)$ & 0.012 \\
\hline rs4355801 & $O P G$ & rs556442 & LRP5 & $8.724(1.936,15.512)$ & 0.012 \\
\hline rs3801387 & WNT16 & rs2982552 & ESR1 & $-8.705(-15.554,-1.855)$ & 0.013 \\
\hline rs556442 & LRP5 & rs9340799 & ESR1 & $9.859(2.045,17.673)$ & 0.013 \\
\hline rs11898505 & SPTBN1 & rs10416265 & GPATCH1 & $-9.200(-16.751,-1.649)$ & 0.017 \\
\hline rs2982552 & ESR1 & rs3020331 & ESR1 & $13.312(2.242,24.381)$ & 0.018 \\
\hline rs2148073 & RANKL & rs1805034 & RANK & $8.443(1.127,15.758)$ & 0.023 \\
\hline rs4869739 & CCDC170 & rs7741021 & RSPO3 & $-7.748(-14.501,-0.995)$ & 0.024 \\
\hline rs2234693 & ESR1 & rs3736228 & LRP5 & $10.606(1.361,19.851)$ & 0.024 \\
\hline rs556442 & $\angle R P 5$ & rs12458117 & RANK & $-9.760(-18.261,-1.258)$ & 0.024 \\
\hline rs3801387 & WNT16 & rs4355801 & $O P G$ & $7.333(0.887,13.777)$ & 0.025 \\
\hline rs2306862 & $\angle R P 5$ & rs9340799 & ESR1 & $8.239(0.973,15.504)$ & 0.026 \\
\hline rs2982552 & ESR1 & rs9340799 & ESR1 & $9.322(1.037,17.606)$ & 0.027 \\
\hline rs7902708 & DKK1 & rs4355801 & $O P G$ & $-8.159(-15.383,-0.934)$ & 0.027 \\
\hline rs2306862 & $\angle R P 5$ & rs4355801 & $O P G$ & $7.779(0.888,14.668)$ & 0.027 \\
\hline rs2306862 & LRP5 & rs11898505 & SPTBN1 & $7.989(0.793,15.183)$ & 0.029 \\
\hline rs556442 & $\angle R P 5$ & rs2234693 & ESR1 & $7.449(0.664,14.233)$ & 0.031 \\
\hline rs3801385 & WNT16 & rs2982552 & ESR1 & $-11.658(-22.351,-0.965)$ & 0.032 \\
\hline rs9340799 & ESR1 & rs7741021 & $\mathrm{RSPO3}$ & $7.191(0.409,13.973)$ & 0.037 \\
\hline rs597319 & TMEM135 & rs851054 & SOST & $6.828(0.405,13.25)$ & 0.037 \\
\hline rs2148073 & RANKL & rs10416265 & GPATCH1 & $-7.879(-15.478,-0.278)$ & 0.042 \\
\hline rs597319 & TMEM135 & rs2908007 & WNT16 & $6.889(0.197,13.579)$ & 0.043 \\
\hline rs3801387 & WNT16 & rs12458117 & RANK & $7.949(0.192,15.704)$ & 0.044 \\
\hline rs2234693 & ESR1 & rs3801385 & WNT16 & $13.418(0.273,26.562)$ & 0.045 \\
\hline rs3018362 & RANK & rs10416265 & GPATCH1 & $7.359(0.114,14.604)$ & 0.046 \\
\hline rs12458117 & RANK & rs7741021 & RSPO3 & $-7.388(-14.744,-0.031)$ & 0.048 \\
\hline rs2908004 & WNT16 & rs4355801 & $O P G$ & $7.273(0.014,14.530)$ & 0.049 \\
\hline
\end{tabular}

SNP1 and SNP2 indicate the individual SNPs within a given SNP-SNP interaction model. Beta represents the regression coefficient. $P$ values are shown adjusted for the covariates sex, age, BMl, physical activity and calcium intake

is implicated in the bone mass acquisition process during early adulthood.

Besides the interaction between LRP5 and ESR1, our model suggested others such as TMEM135-WNT16, ESR1-DKK1 or OPG-LRP5. Interestingly, all of these genes belong to well characterize pathways implicated in the complex mechanisms that regulate bone formation. Thus, a novel line of research would be very interesting to elucidate how they may be interacting at the molecular level.

On the other hand, SNP-SNP interactions between variants that were not in $L D$ within the same gene were observed. That was the case of genes WTN16, LPR5 and
ESR1. Thus, beyond the individual effect of SNPs in a gene, epistatic SNP-SNP interactions in the same gene occur and could be a potential factor contributing to the unexplained heritability of bone mass acquisition.

On the other hand, it could be hypothesised that the effects of SNP-SNP interactions would be weak and therefore, a very large population size would be needed to detect associations surpassing the $p$ value threshold for multiple testing $(\mathrm{p}<0.0001)$. Thus, a limitation of the present study could be the population size included that would not reach enough statistical power to detect epistatic SNP-SNP interactions with weak effect. Therefore, in order to support our preliminary results, further 
studies including larger population size and metaanalysis are needed. On the other hand, the current approach considered only two-locus interactions and therefore more complex interactions between three or more genetic markers are unknown. Again, larger studies are required to confirm our findings and to elucidate mechanisms by which the genetic interaction between these genes influences quantitative bone phenotypes in early adulthood.

\section{Conclusions}

Our analysis of SNP-SNP interaction in candidate genes of QUS in Caucasian young adults reveal several interactions, especially between ESR1 and LRP5 genes, that did not reach statistical significance. Although our results do not support a relevant genetic contribution of SNP-SNP epistatic interactions to QUS in young adults, further studies in larger independent populations would be necessary to support these preliminary findings.

\section{Abbreviations}

BMD: Bone mineral density; BMI: Body mass index; BUA: Broadband ultrasound attenuation; Cls: Confidence intervals; DCl: Dietary calcium intake; DXA: Dual-energy x-ray absorptiometry; GWAS: Genome wide association studies; HWE: Hardy-Weinberg equilibrium; IPAQ: International Physical Activity Questionnaire; MAF: Minor allele frequency; PBM: Peak bone mass; QUS: quantitative ultrasound

\section{Acknowledgements}

Not applicable.

\section{Funding}

This study was supported by a grant PI-0414-2014 from Consejería de Salud (Junta de Andalucía, Spain). Correa-Rodríguez M is a predoctoral fellow (FPU13/ 00143) from the Ministerio de Educación, Cultura y Deporte (Programa de Formación del Profesorado Universitario).

\section{Availability data and materials}

The datasets during and/or analysed during the current study available from the corresponding author on reasonable request.

\section{Authors' contributions}

M C-R and J S-RV monitored data collection and drafted and revised the paper. S V and J M wrote the statistical analysis plan, cleaned and analyzed the data. B R-M and G O analyzed the data, and drafted and revised the paper. All authors have approved the manuscript.

\section{Ethics approval and consent to participate}

This study met the institutional and/or national research committee as well as 1964 Helsinki declaration and its later amendments ethical standards for procedures involving human participants. All study participants gave their written informed consent and the local ethics committee of the University of Granada (Spain) approved the study (78/CEIH/2015).

\section{Consent for publication}

Not applicable.

\section{Competing interests}

Gisela Orozco is a member of the Editorial Board. The authors declare that they have no competing interests.

\section{Publisher's Note}

Springer Nature remains neutral with regard to jurisdictional claims in published maps and institutional affiliations.

\section{Author details}

'Faculty of Health Sciences, University of Granada, Av. Ilustración, 60, 18016 Granada, Spain. ${ }^{2}$ Arthritis Research UK Centre for Genetics and Genomics, Centre for Musculoskeletal Research, Faculty of Biology, Medicine and Health, Manchester Academic Health Science Centre, The University of Manchester, Oxford Road, Manchester M13 9PT, UK.

Received: 22 May 2017 Accepted: 27 September 2017

Published online: 03 October 2017

\section{References}

1. Johnell O, Kanis JA. An estimate of the worldwide prevalence and disability associated with osteoporotic fractures. Osteoporos. 2006;17:1726-33.

2. Shuler FD, Conjeski J, Kendall D, Salava J. Understanding the burden of osteoporosis and use of the World Health Organization FRAX. Orthopedics. 2012;35:798-805.

3. NIH Consensus Development Panel on Osteoporosis Prevention, Diagnosis, and Therapy. Osteoporosis prevention, diagnosis, and therapy. JAMA. 2001; 285(6):785-95.

4. Ralston $\mathrm{SH}$, de Crombrugghe $\mathrm{B}$. Genetic regulation of bone mass and susceptibility to osteoporosis. Genes Dev. 2006;20:2492-506.

5. Ralston $\mathrm{SH}$. Genetic control of susceptibility to osteoporosis. J Clin Endocrinol Metab. 2002;87:2460-6.

6. Berger C, Goltzman D, Langsetmo L, Joseph L, Jackson S, Kreiger N, et al. Peak bone mass from longitudinal data: implications for the prevalence, pathophysiology, and diagnosis of osteoporosis. J Bone Miner Res. 2010;25:1948-57.

7. Guéguen R, Jouanny P, Guillemin F, Kuntz C, Pourel J, Siest G. Segregation analysis and variance components analysis of bone mineral density in healthy families. J Bone Miner Res. 1995;10:2017-22.

8. Pocock NA, Eisman JA, Hopper JL, Yeates MG, Sambrook PN, Eberl S. Genetic determinants of bone mass in adults. A twin study. J Clin Invest. 1987;80:706-10.

9. Moayyeri A, Adams JE, Adler RA, Krieg M-A, Hans D, Compston J, et al. Quantitative ultrasound of the heel and fracture risk assessment: an updated meta-analysis. Osteoporos Int. 2012;23:143-53.

10. McCloskey EV, Kanis JA, Odén A, Harvey NC, Bauer D, González-Macias J, et al. Predictive ability of heel quantitative ultrasound for incident fractures: an individual-level meta-analysis. Osteoporos Int. 2015;26:1979-87.

11. Krieg MA, Barkmann R, Gonnelli S, Stewart A, Bauer DC, Del Rio BL, et al. Quantitative Ultrasound in the Management of Osteoporosis: The 2007 ISCD Official Positions. J Clin Densitom. 2008;11:163-87.

12. Gregg EW, Kriska AM, Salamone LM, Roberts MM, Anderson SJ, Ferrell RE, et al. The epidemiology of quantitative ultrasound: a review of the relationships with bone mass, osteoporosis and fracture risk. Osteoporos Int. 1997:7:89-99.

13. Marín F, González-Macías J, Díez-Pérez A, Palma S, Delgado-Rodríguez M. Relationship between bone quantitative ultrasound and fractures: a meta-analysis. J Bone Miner Res. 2006;21:1126-35.

14. Glüer CC. Monitoring skeletal changes by radiological techniques. J Bone Miner Res. 1999;14:1952-62.

15. Estrada K, Styrkarsdottir U, Evangelou E. Genome-wide meta-analysis identifies 56 bone mineral density loci and reveals 14 loci associated with risk of fracture. Nat Genet. 2012;44:491-501.

16. Rivadeneira F, Styrkársdottir U, Estrada K, Halldórsson BV, Hsu Y-H, Richards JB, et al. Twenty bone-mineral-density loci identified by large-scale meta-analysis of genome-wide association studies. Nat Genet. 2009;41:1199-206.

17. Duncan EL, Danoy P, Kemp JP, Leo PJ, McCloskey E, Nicholson GC, et al Genome-Wide Association Study Using Extreme Truncate Selection Identifies Novel Genes Affecting Bone Mineral Density and Fracture Risk. PLoS Genet. 2011;7:e1001372

18. Moayyeri A, Hsu Y-H, Karasik D, Estrada K, Xiao S-M, Nielson C, et al. Genetic determinants of heel bone properties: genome-wide association meta-analysis and replication in the GEFOS/GENOMOS consortium. Hum Mol Genet. 2014;23:3054-68.

19. Lin C, Chu CM, Lin J, Yang HY, Su SL. Gene-gene and gene-environment interactions in meta-analysis of genetic association studies. PLoS One. 2015:10:1-13.

20. Pérez A, Ulla M, García B, Lavezzo M, Elías E, Binci M, et al. Genotypes and clinical aspects associated with bone mineral density in Argentine postmenopausal women. J Bone Miner Metab. 2008;26:358-65. 
21. Rivadeneira F, van Meurs JBJ, Kant J, Zillikens MC, Stolk L, Beck TJ, et al. Estrogen receptor beta (ESR2) polymorphisms in interaction with estrogen receptor alpha (ESR1) and insulin-like growth factor I (IGF1) variants influence the risk of fracture in postmenopausal women. J Bone Miner Res. 2006;21:1443-56

22. Zupan J, Mencej-Bedrač S, Jurković-Mlakar S, Preželj J, Marc J, Mencej-Bedrac S, et al. Gene-gene interactions in RANK/RANKL/OPG system influence bone mineral density in postmenopausal women. J Steroid Biochem Mol Biol. 2009;118:102-6.

23. Hsu YH, Niu T, Terwedow HA, Xu X, Feng $Y$, Li Z, et al. Variation in genes involved in the RANKL/RANK/OPG bone remodeling pathway are associated with bone mineral density at different skeletal sites in men. Hum Genet. 2006:118:568-77.

24. Yang T-L, Guo Y, Li J, Zhang L, Shen H, Li SM, et al. Gene-gene interaction between RBMS3 and ZNF516 influences bone mineral density. J Bone Miner Res. 2013;28:828-37.

25. Patel MS, Cole DE, Smith JD, Hawker GA, Wong B, Trang $H$, et al. Alleles of the estrogen receptor alpha-gene and an estrogen receptor cotranscriptional activator gene, amplified in breast cancer-1 (AIB1), are associated with quantitative calcaneal ultrasound. J Bone Miner Res. 2000;15:2231-9.

26. Giguère $Y$, Dodin S, Blanchet $C$, Morgan $K$, Rousseau F. The association between heel ultrasound and hormone replacement therapy is modulated by a two-locus vitamin D and estrogen receptor genotype. J Bone Miner Res. 2000;15:1076-84.

27. Koh J-M, Nam-Goong IS, Hong JS, Kim H-K, Kim JS, Kim S-Y, et al. Oestrogen receptor alpha genotype, and interactions between vitamin $D$ receptor and transforming growth factor-beta1 genotypes are associated with quantitative calcaneal ultrasound in postmenopausal women. Clin Endocrinol. 2004;60:232-40.

28. Correa-Rodríguez M, Schmidt Rio-Valle J, Rueda-Medina B. Polymorphisms of the WNT16 gene are associated with the heel ultrasound parameter in young adults. Osteoporos Int. 2015;27:1057-61.

29. García-Ibarbia C, Pérez-Núñez MI, Olmos JM, Valero C, Pérez-Aguilar MD Hernández JL, et al. Missense polymorphisms of the WNT16 gene are associated with bone mass, hip geometry and fractures. Osteoporos Int. 2013;24:2449-54.

30. Correa-Rodríguez M, Schmidt-RioValle J, Rueda-Medina B. The rs3736228 polymorphism in the LRP5 gene is associated with calcaneal ultrasound parameter but not with body composition in a cohort of young Caucasian adults. J Bone Miner Metab. 2016;27

31. Craig CL, Marshall AL, Sjostrom M, Bauman AE, Booth ML, Ainsworth BE, Pratt M, Ekelund U, Yngve A, Sallis SJ, Oja P. International Physical Activity Questionnaire: 12 Country Reliability and Validity. Med Sci Sport Exerc. 2003:35:3508-1381.

32. Töyräs J, Nieminen MT, Kröger $H$, Jurvelin JS. Bone mineral density, ultrasound velocity, and broadband attenuation predict mechanical properties of trabecular bone differently. Bone. 2002;31:503-7.

33. Gennari L, Merlotti D, De Paola V, Calabrò A, Becherini L, Martini G, et al. Estrogen receptor gene polymorphisms and the genetics of osteoporosis: A HuGE review. Am J Epidemiol. 2005:307-20.

34. Gruber CJ, Tschugguel W, Schneeberger C, Huber JC. Production and Actions of Estrogens. N Engl J Med. 2002:346:340-52.

35. Paech K, Webb P, Kuiper GG, Nilsson S, Gustafsson J, Kushner PJ, et al. Differential ligand activation of estrogen receptors ERalpha and ERbeta at AP1 sites. Science American Association for the Advancement of Science. 1997;277:1508-10.

36. Gong Y, Slee RB, Fukai N, Rawadi G, Roman-Roman S, Reginato AM, et al. $L D L$ receptor-related protein 5 (LRP5) affects bone accrual and eye development. Cell. 2001;107:513-23.

37. Kumar J, Swanberg M, McGuigan F, Callreus M, Gerdhem P, Akesson K. LRP4 association to bone properties and fracture and interaction with genes in the Wnt- and BMP signaling pathways. Bone. 2011:49:343-8.

38. Saarinen A, Välimäki V-V, Välimäki MJ, Löyttyniemi E, Auro K, Uusen P, et al, The A1330V polymorphism of the low-density lipoprotein receptor-related protein 5 gene (LRP5) associates with low peak bone mass in young healthy men. Bone. 2007;40:1006-12.

39. Koller DL, Zheng HF, Karasik D, Yerges-Armstrong L, Liu CT, McGuigan F, et al. Meta-analysis of genome-wide studies identifies WNT16 and ESR1 SNPs associated with bone mineral density in premenopausal women. J Bone Miner Res. 2013;28:547-58.
40. Piters E, de Freitas F, Nielsen TL, Andersen M, Brixen K, Van Hul W. Association study of polymorphisms in the SOST gene region and parameters of bone strength and body composition in both young and elderly men: data from the Odense Androgen Study. Calcif Tissue Int. 2012;90:30-9.

41. Cheung C-L, Huang Q-Y, Chan V, Kung AWC. Association of low-density lipoprotein receptor-related protein 5 (LRP5) promoter SNP with peak bone mineral density in Chinese women. Hum Hered. 2008;65:232-9.

\section{Submit your next manuscript to BioMed Central and we will help you at every step:}

- We accept pre-submission inquiries

- Our selector tool helps you to find the most relevant journal

- We provide round the clock customer support

- Convenient online submission

- Thorough peer review

- Inclusion in PubMed and all major indexing services

- Maximum visibility for your research

Submit your manuscript at www.biomedcentral.com/submit

) Biomed Central 